\title{
BMJ Open Creating psychological connections between intervention recipients: development and focus group evaluation of a group singing session for people with aphasia
}

\author{
Mark Tarrant, ${ }^{1,2}$ Krystal Warmoth, ${ }^{1}$ Chris Code ${ }^{3}$ Sarah Dean, ${ }^{1,2}$ \\ Victoria A Goodwin, ${ }^{1,2}$ Ken Stein, ${ }^{1,2}$ Thavapriya Sugavanam ${ }^{2,4}$
}

To cite: Tarrant $\mathrm{M}$, Warmoth K, Code C, et al. Creating psychological connections between intervention recipients: development and focus group evaluation of a group singing session for people with aphasia. BMJ Open 2016;6: e009652. doi:10.1136/ bmjopen-2015-009652

- Prepublication history for this paper is available online. To view these files please visit the journal online (http://dx.doi.org/10.1136/ bmjopen-2015-009652).

Received 7 August 2015 Revised 4 December 2015 Accepted 7 December 2015

CrossMark

For numbered affiliations see end of article.

Correspondence to Dr Mark Tarrant; m.tarrant@exeter.ac.uk

\section{ABSTRACT}

Objectives: The study sought to identify key design features that could be used to create a new framework for group-based health interventions. We designed and tested the first session of a group intervention for stroke survivors with aphasia which was aimed at nurturing new psychological connections between group members.

Setting: The intervention session, a participant focus group and interviews with intervention facilitators were held in a local community music centre in the South West of England.

Participants: A convenience sample of 10 community-dwelling people with poststroke aphasia participated in the session. Severity of aphasia was not considered for inclusion.

Intervention: Participants took part in a 90-min group singing session which involved singing songs from a specially prepared song book. Musical accompaniment was provided by the facilitators.

Primary and secondary outcome measures: Participants and group facilitators reported their experiences of participating in the session, with a focus on activities within the session related to the intervention aims. Researcher observations of the session were also made.

Results: Two themes emerged from the analysis, concerning experiences of the session ('developing a sense of group belonging') and perceptions of its design and delivery ('creating the conditions for engagement'). Participants described an emerging sense of shared social identity as a member of the intervention group and identified fixed (eg, group size, session breaks) and flexible (eg, facilitator responsiveness) features of the session which contributed to this emergence. Facilitator interviews and researcher observations corroborated and expanded participant reports.

Conclusions: Engagement with health intervention content may be enhanced in group settings when intervention participants begin to establish positive and meaningful psychological connections with other group members. Understanding and actively nurturing these

\section{Strengths and limitations of this study}

The study addressed a recognised gap in knowledge about how new group-based health interventions can be designed and delivered.

- The study adopts an evidence-based approach to assembling new groups for the delivery of health interventions and identifies and defines a set of core (group) intervention features.

- The study provides triangulation of findings, drawing on data from three sources (a focus group, interview with group facilitators and research observations of the intervention session).

- While the findings resonate with previously reported general processes of group formation, the conclusions are drawn from data from a single session of group singing for people with one health condition.

- Participants were clear about the potential health and well-being benefits of participating in group interventions like the one studied here, but it is not possible to conclude definitively that this participation actually affected health. Additional research, employing other research designs, is needed to address this question.

connections should be a core feature of a general framework for the design and delivery of group interventions.

Groups are employed to deliver healthrelated interventions in a variety of domains, including rehabilitation, ${ }^{1}$ health promotion ${ }^{2}$ and the management of long-term conditions such as multiple sclerosis ${ }^{3}$ and stroke. ${ }^{4}$ Groups are often assumed to be cost-effective, relative to individual interventions, ${ }^{6}$ although there is a recognised lack of data in this regard. ${ }^{2}$ Moreover, the observed heterogeneity in their design and delivery 
highlights a need for greater detail in the reporting of group interventions, particularly given the increasing frequency with which they are being employed. ${ }^{78}$

The current research aimed to inform a guidance framework for the development and delivery of new group interventions for long-term health conditions, in accordance with the Medical Research Council's modelling phase of complex intervention development and evaluation. ${ }^{9-11}$ We designed, delivered and evaluated an introductory session of a group intervention for stroke survivors with aphasia. Besides impaired language function, people with aphasia experience a range of health problems that negatively affect psychosocial functioning, including social isolation and distress, which are not typically addressed in speech and language rehabilitation programmes. ${ }^{12}{ }^{13}$ Group-based interventions may be a way of addressing psychosocial functioning needs of people with long-term conditions such as aphasia, by providing valuable opportunities for social interaction and fostering the rebuilding of core skills (eg, social participation, confidence) ${ }^{14}$ In support of this idea, observational, experimental and qualitative studies have suggested that psychosocial problems may be addressed in some group contexts. ${ }^{415} 16$

Our study drew on principles of social identity theory, ${ }^{17}$ which holds that the psychological connections members of a social group establish with each other structure their attitudes, cognitions and behaviours, including those related to health. ${ }^{18}$ Belonging to a social group, and valuing that membership, is an important basis for psychological well-being. ${ }^{16}{ }^{18-20}$ Although the benefits of group membership have been demonstrated across a range of health conditions, including long-term conditions such as multiple sclerosis, ${ }^{3}$ much less is known about how social identity can be actively nurtured in new group settings. Social identity is unlikely to emerge spontaneously as a result of merely bringing people together in a new group ${ }^{21}$ and, we suggest, needs to be carefully nurtured through the actions of the group facilitator(s).$^{22}$ Because of the inevitable variability between people in medical (eg, physical functioning), psychological (eg, symptom perceptions) and wider sociological (eg, socio-economic status) factors, fostering the development of a common frame of reference and shared social identity in participants seems necessary to prevent the factions and schism that may otherwise occur in novel group settings. ${ }^{23}$

Our study sought to identify key features that could be used to design a framework for creating social identity in new group interventions. Because feeling psychologically connected to a group is strongly associated with group commitment, or loyalty, ${ }^{24}$ nurturing an early and positive sense of social identity is likely to motivate participant attendance at subsequent sessions of an intervention programme and encourage more ready engagement with intervention material and participant interaction. Establishing social identity could be a key variable influencing the progression of group interventions. For this reason, we focused on the introductory session of an intervention.

The intervention we focused on was organised around a programme of group singing for people with aphasia. Numerous examples exist of community-based singing groups for people with such long-term conditions, and there is a growing research interest in the potential benefits of group singing on well-being and quality of life, both for healthy populations and those with long-term conditions such as aphasia. ${ }^{25}$ Some uncontrolled and qualitative studies have suggested that singing groups may help address the psychosocial needs of people with long-term conditions such as aphasia, ${ }^{26-28}$ although there is a lack of rigorous data concerning both the health benefits of participation in such group interventions and their design and delivery. ${ }^{7}$

Objectives/aims. The aim of this study was to deliver an introductory session of a new group intervention and explore participants' experiences of it. Specifically, the study examined participants' experiences of taking part in the session in terms of (A) its capacity to nurture psychological connections between participants (shared social identity) and (B) barriers and facilitators of participants' engagement with it.

\section{METHOD \\ Design}

A qualitative approach was selected on the basis of a constructionist epistemology. We utilised the constructionist assumption that the 'truth' has multiple meanings and is subject to individual interpretation and the context of the current situation ${ }^{29}{ }^{30}$ but retained a theoretically underpinned approach grounded in principles of social identity theory because this combination of approaches was in line with our exploratory aims. Our approach combined non-participant observation of the introductory session of the group singing intervention, a focus group with session participants and individual interviews with music facilitators.

\section{Sample}

A convenience sample of stroke survivors with aphasia $(\mathrm{n}=10)$ was recruited through a local network for people with aphasia. Severity of aphasia was not considered for inclusion. Potential participants were initially contacted with the assistance of a local co-ordinator of an aphasia network who was also a stroke survivor with aphasia. Those interested in taking part in the study were provided with an information sheet explaining that they would be asked to attend the singing session and contribute to a focus group; written consent was obtained from each participant. Participants were told that they were free to withdraw from the study at any time (none did). A local charity-funded music organisation supplied the music facilitators and provided space for the singing session and focus group/interviews. Participants were reimbursed for their travel expenses. 


\section{Development of the group singing session}

The singing session was designed with input from stroke survivors with aphasia, music facilitators, a speech and language therapist, health researchers and psychologists, following principles of participatory design. ${ }^{31}{ }^{32}$ Two design meetings were held. The first meeting produced the outline of the singing session, with a focus on describing group activities designed to encourage the emergence of a social identity, as members of the singing group, among the participants. Specifically, the outline described structural (eg, seating arrangements, session break), musical (eg, using familiar, upbeat songs to maximise participant engagement) and facilitator-led (acknowledging group progress and providing feedback) initiatives to promote and reward interaction between participants and create for them a shared perception of commonality, and group commitment, consistent with social identity theory principles. ${ }^{1724}$ The session outline was refined in the second meeting, which additionally focused on potential barriers to participant engagement with the singing session (eg, lacking confidence in language) and identifying procedures to minimise these (eg, avoiding group member introductions at the session outset). CC and a speech and language therapist advised on potential barriers to participant communication and contributed to the topic schedule used to guide the focus group.

\section{Research context and data collection}

The singing session was led by two experienced music facilitators and was observed by four of the authors (TS, KW, KS and MT) who made independent session notes. The session lasted $1.5 \mathrm{~h}$ and began with a brief introduction to the session by the facilitators and a short physical and vocal warm-up activity. Participants then took part in two focused singing blocks, led by the music facilitators, separated by a short refreshment break. Participants were each provided with a songbook containing lyric sheets. The first singing block focused on singing songs preselected by facilitators to take account of the anticipated musical preferences of participants on the basis of their ages. ${ }^{33}$ The second singing block continued in the manner of the first block but additionally involved some repetition of songs and rehearsal of different song elements, including introducing harmonies.

After the singing session, TS led a 45-min focus group with the participants. The music facilitators were then interviewed ( $45 \mathrm{~min}$ ) by TS using a semistructured interview guide to explore their reflections on the singing session, focusing on activities within the session related to the underlying theoretical aims. The interview guide was reviewed and agreed by the authors prior to use. The focus group and facilitator interviews were audio recorded.

\section{Data analysis}

Audio recordings were transcribed verbatim. The Framework Approach, ${ }^{34}$ a widely used approach in applied qualitative research, guided the data analysis. NVivo10 qualitative data analysis software was used to support data management. TS and KW independently read the transcripts numerous times to become familiarised with the data. Initial ideas were then identified and coded using both inductive and deductive processes. A thematic framework was developed with the codes as columns and data sources as rows (ie, focus group, facilitator interviews, researcher observations). Through comparison of codes and emerging themes, the framework was further refined, and thematic charts were created incorporating the coded data. The resulting themes and subthemes were then independently verified by SD and, through discussion, interpretation arising from the analysis was finalised.

\section{RESULTS}

Ten stroke survivors with aphasia (five males, five females) took part in the singing session and focus group. A carer of one participant also attended the session but did not participate in any activities. Participants' mean age was 58.60 years $(\mathrm{SD}=6.93)$. Stroke type included four participants who had had an ischemic stroke, one a haemorrhagic stroke and one a subarachnoid haemorrhage (the remaining participants did not know their type of stroke). Mean time since stroke was 7.70 years $(\mathrm{SD}=8.40)$.

As is reflected in the section below, some participants appeared more willing (and able) to contribute to the focus group discussion than other participants. However, it was clear from other contributions (eg, non-verbal communication) that these participants agreed with the sentiments expressed in the focus group by more vocal members. The researcher observations of the singing session and the facilitator interviews corroborate this interpretation: there was nothing to suggest that any of the less vocal participants in the focus group experienced the singing session differently from the more vocal participants.

Two inter-related themes emerged from the analysis of the focus group and facilitator interview data that concerned participants' experiences of the singing session (Developing a sense of group belonging) and their perceptions of the session design and delivery (Creating the conditions for engagement). Within these two themes, eight key features were identified that could be used to design a framework for developing social identity in new group interventions (figure 1). These features are described in detail below, supported by quotes from participants and music facilitators, and also the researchers' observation notes. Participant and facilitator names below are pseudonyms.

\section{Theme 1: Developing a sense of group belonging}

This theme described how the singing session provided the foundations for developing psychological connections between group members and a sense of belonging, characterised by being comfortable in the group and 
Figure 1 Key features reflecting

participant experiences of an introductory session of a new group singing intervention for people with aphasia.

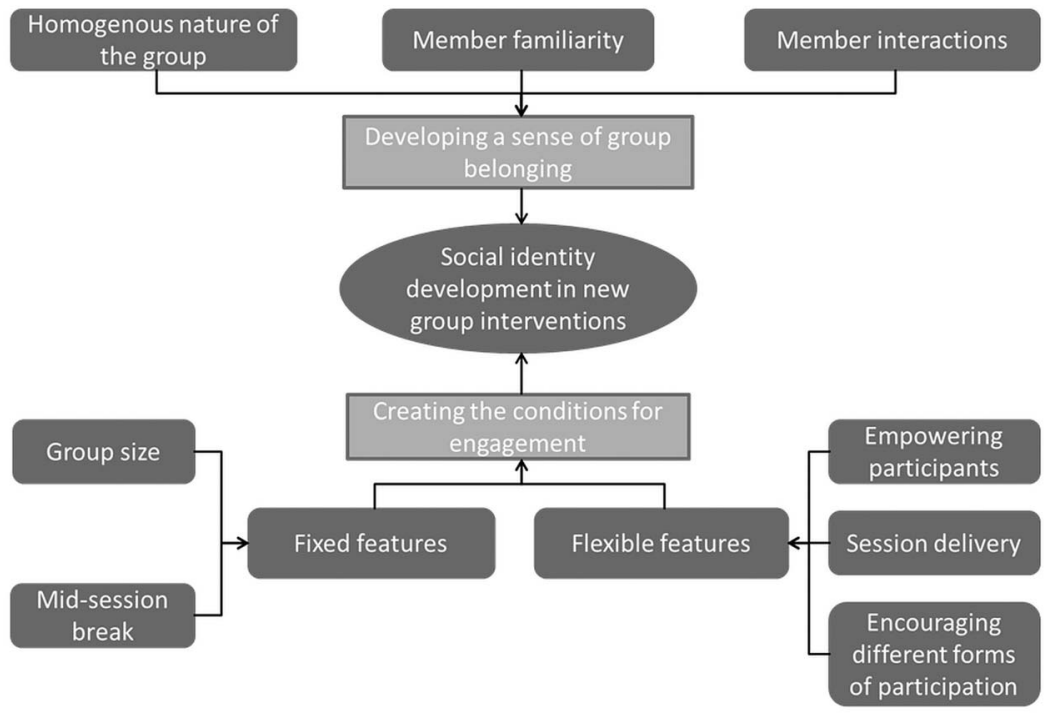

interacting with others. Three key features that emerged within this theme are as follows:

(i) Homogenous nature of the group: Sharing a health condition (in this case, aphasia) with every other member of the singing group was described by participants as critical to them feeling at ease, or comfortable, with the group. Homogeneity of condition also promoted a sense of common understanding between participants and was seen as a starting point for forming connections with one another.

... because we all have had brain problems it connects you all. [Megan]

I think it is a good thing because everybody here understands what's going on in your head and you can talk to people about it ... if I talk to Julie or Rob about it or Ben, then they understand, don't you? Understand what's happened to you and what the pitfalls are or the obstacles are. [Jack]

(ii) Member familiarity: Each participant knew at least one other group member in advance of attending the singing session, and everyone knew the local aphasia network co-ordinator, Julie. This was regarded as contributing positively to participants' engagement with the session and appeared to influence the rapid emergence of a positive group dynamic.

Because most of us know at least a few people here and we talk to them, so it is not mainly a problem. [Ben]

... they actually settled very quickly. There was a common understanding perhaps between them. [Beth, music facilitator]

Notably, presession member familiarity was described by some participants as a factor which would determine their decision to attend a group programme such as this.
If you have got a group who didn't know anybody, then I don't think anyone would turn up. You would have to get a certain type to get them to turn up initially. I came because Julie asked me, not because of any other reason. [Ben]

... Julie really brought everybody here together, so she knows everybody that solves it, it makes it fairly easy really. [Ben]

(iii) Member interactions: There were numerous instances of interpersonal interaction during the singing session (including non-verbal interaction such as eye contact and the expression of emotions). Beth, the music facilitator, was of the view that 'they [the participants] had a lovely way of being with each other too. There was a lot of support in there, just by little glances, encouraging glances here and there from people or laughter and quite spontaneous things that went on'. Interaction often occurred between participants previously unfamiliar with each other: Ben felt he had 'spoken to people who I have not spoken to before'.

Interaction also occurred between the group members and the music facilitators. This interaction was experienced positively by the participants and encouraged further engagement with the singing session. Indeed, member-facilitator interactions were deemed essential for participants to provide feedback, for facilitators to adapt and make changes accordingly and, overall, to motivate participation.

... they were very responsive ... I was very aware at the start, it was quite hard to get any eye contact with anybody in the circle because everybody was so fixated on that song book ... So I initiated a conversation with somebody about a song and the words and,...So they weren't saying it is not something they want to do but [it] brought our attention to the fact that reading the lyrics and the singing was a bit of [a] thing which is why we kind of adapted to try and suggest that they shut their song books. That's when we invited them to shut the 
books and do some work off the song book and trying to join in. [Susan, music facilitator]

By coming to feel more comfortable with the group, participants felt able to relax and reported reduced anxiety. Indeed, it was apparent that participants and facilitators were initially anxious about the singing group, and this anxiety was reflected in individual contributions to the session, especially at the beginning of it.

I think it will be [like this] in the first session ... I was a little bit embarrassed singing but I did do it but it was very quiet singing I think. I don't think we sang as we should do because we were a little bit self-conscious. [Jack]

We work a lot with people who are nonverbal in different contexts and we have worked with people with aphasia but not a group of people with aphasia, so it was a different thing and we were worried, a little bit worried about people feeling uncomfortable and how we might ... avoid that happening. [Beth, Music facilitator]

Well, you know that [there is] always is going to a bit of anxiety... at the start of the session, may be as to know what to expect and as to what is expected of them. [Susan, Music facilitator]

However, the inhibitions that participants reported largely dissipated as the session progressed. Participants and facilitators referred to the positive interactions as possible reason for this.

... the body language has changed, they were moving more, the feet were going up, a bit more wriggling about, and lots of smiling, nice body movement along with the poses and the music .... [Beth, music facilitator]

we have got to be at ease in any group, in any situation, but particularly a group that may be anxious, just maybe that would help. It did feel that as soon we had that interaction, then ... it was different. [Beth, Music facilitator]

The three features of this theme (group homogeneity, member familiarity and interaction) contributed to the emerging sense of belonging and connection, or shared social identity that participants experienced as a result of taking part in the singing session. These features also underpinned their beliefs about the potential longer-term health impacts of the intervention. Participants were unanimous in their belief that a programme of singing sessions like the current one had the potential to positively influence quality of life. Some participants elaborated on this belief by describing other health benefits that may arise from belonging to and participating in groups like this, including improved confidence and coping with daily stressors. Expectations about health benefits appeared to influence participants' engagement with the session.
I think in a small group like this, we are so involved when we are singing and you got to put yourself up and I think because of that you are you get more comfortable with other people, because of that you get more confident with people. [Jack]

\section{Theme 2: Creating the conditions for group engagement}

Theme 1 was concerned with how participants experienced the singing session and identified factors that contributed to an emerging sense of shared social identity. Theme 2 reflected participants' and facilitators' perceptions of the session features that created the conditions for establishing the psychological connections underpinning this identity. There were two subthemes within this theme, one reflecting fixed, or planned, features of the singing session, and one reflecting flexible, or responsive, features of it.

\section{Fixed features}

(i) Group size: Participants suggested that intervention groups like this should involve a maximum of around 15 people. They felt that interventions with larger groups than this would inhibit one-to-one interaction with the facilitators-interaction that they regarded as contributing to the group's success.

Well, the more person you put in, you don't reach the purpose of it because you can't talk, and ... if you [are] trying to talk to the people here, you would want to talk to everybody, won't you? And the facilitators would need them and this meeting would not be the same because some people would not be able to say what they wanted to say. [Jack]

(ii) Mid-session break: The 15-20-min mid-session break presented an opportunity for further interaction. The positive dynamic this created spilled over into the second half of the singing session. Participants and facilitators valued highly the mid-session break.

... you need that, have that to say 'hi, how are you' and that was good as well ... and then we came back, our singing I think went up after [that]. [Julie]

... we have a rapport built between participants and ourselves, and also with each other there was a lot of discussion and lot of hustle and bustle going on really in the break time and it became more visible in the second part that people were more joking and laughing with each other across the room more so than in the first half. [Beth, music facilitator]

This narrative resonates with the researchers' observations of the singing session. Early in the session, several participants were observed to be hesitant in contributing to the group singing; however, after the break, it was apparent that the group dynamic had shifted such that those whose contributions were previously muted were now fully participatory. 
Flexible features

(1) Session delivery: Although certain aspects of the singing session, such as the break and the group size, were planned in advance of the session, the facilitators adopted a flexible approach to the session delivery that was based on their own judgement as to how the session was progressing and in response to verbal and nonverbal feedback from participants. For example, while the mid-session break was initially scheduled for $10 \mathrm{~min}$, this was allowed to over-run because of the high level of interaction that was occurring between participants.

The facilitators emphasised the necessity of this flexibility in order to respond to the needs of the group.

Every group is going to be different and dynamic and you need to be able to respond to the groups as they are [Susan, music facilitator]

It is important to have a kind of awareness of things that might happen ... that might be an issue so that you can plan for it. But aside from that, it is good to have that opportunity, those windows to explore because then you get that nice surprises of things, you just try that and then you just might hit on something really really positive and really powerful for somebody. [Beth, music facilitator]

Participants valued this approach too, although at the same time emphasised the importance of the intervention meeting their expectations. Expectations that were not met could negatively influence participants' motivation to attend subsequent group sessions.

Personally I would like to have some achievement by the end of some sorts if that is a possibility and I don't know something like a choir or with progress. [Rob]

I think what they [facilitators] did was very good but yeah if you did that every week and not anything else, then I wouldn't come as there would not be anything for me. I think the first couple of weeks would be alright but after that you know. [Jack]

For Jack to continue in the programme, the intervention would need to focus on speech development: he said he would not attend if the intervention comprised only "sing along" sessions.

(2) Encouraging different forms of participation: Relatedly, the flexibility of the session allowed facilitators to introduce new activities that enabled different forms of participation. At one point in the session, facilitators encouraged participants to use a kazoo. The session observers noted participants' enjoyment of this nonsinging activity, a view also expressed in the focus group and facilitator interviews.

... anybody who is feeling a bit ... something else they can concentrate on. [Cath]

It is an excellent breathing exercise I think. [Megan]
... quite empowering for them, they were waiting for the end of the song so that they could make that noise. [Beth, music facilitator]

Use of instruments in this way was felt to create an additional form of participation in the group beyond singing, and this was seen as particularly valuable for participants with more severe aphasia who are less able to vocalise.

Yes everybody did really enjoy it [the kazoo]. They took risks themselves and for the lady that had quite profound aphasia, she ... and the gentleman next to her in the end, for them it was very marked, because they were making the big noise. They both really liked that I think. They were really into it. [Susan, music facilitator]

(3) Empowering participants: Facilitators also sought opportunities for providing participants with some control over the session content, through collectively choosing the songs that the group would sing. Facilitators felt that this sense of participant control was important and contributed to a feeling of collective ownership over the group and its direction.

\begin{abstract}
We were probably also trying to promote some more choice making, so that the participants would perhaps decide ... we can introduce new material but choose the one [song] they are most comfortable with and the ones they would want to spend time on. [Beth, music facilitator]
\end{abstract}

Another way in which participants were empowered within the session was by allowing singing/musical mistakes to happen and by encouraging participants to take singing 'risks'.

... for the participants to be able to make mistakes and think not to be a problem, nobody is judging them, so it's ok to kind of expose yourself to those kind of ... challenges [Susan, music facilitator]

In summary, the above five features in combination reflected the perceived design and delivery elements of the singing session which allowed for the emergence of shared social identity between participants described in Theme 1.

\section{DISCUSSION}

We designed and delivered an introductory session of a new group intervention for people with aphasia. Data from a focus group with intervention participants, an interview with group facilitators and direct observations of the session highlighted an emerging sense of group belonging and social identity among participants. This emerging social identity was underpinned by shared perceptions of group homogeneity, member familiarity and social interaction (figure 1). The findings from this study support previous research that has established social identity as an important determinant of a range of health 
outcomes. ${ }^{18} 28$ Our research extends that earlier work by showing how social identity can be actively nurtured in new group interventions. This contribution is important given the increasing frequency with which new patient groups are assembled for the purposes of delivering health interventions. Understanding how new social identities emerge, and knowledge of the factors that can inhibit or facilitate this emergence, is an important first step in developing a new guidance framework to enhance group-based interventions for health.

Our study highlights some potential benefits of establishing early psychological connections and a sense of group belonging among intervention participants. Principally, the study shows that actively shaping intervention participants' experiences of new groups can encourage engagement with an intervention, partly because it can reduce the anxiety that participants experience in new group settings; nurturing shared social identity can provide the foundation for effective delivery of intervention content. Accordingly, to the extent that participants feel comfortable in engaging with an intervention group, it is possible that the health potential of the given intervention will be better realised. Participants in the current study were clear about the potential health benefits of this intervention, namely increasing confidence and quality of life-outcomes especially pertinent to their health condition (aphasia). These anticipated benefits were attributed to the reported ease with which participants interacted with other members.

While our study has focused on a bespoke group intervention for a specific health condition, we suggest that the basic principles needed to establish belonging and psychological connections-shared social identity-that have been documented here should be core features of a general framework for group interventions, including those targeting health outcomes beyond psychosocial health. ${ }^{8}$ By way of an example, recent research with bariatric surgery candidates has highlighted the role of shared social identity in motivating engagement with a group dietary education programme and subsequent lifestyle behaviour change (Tarrant et al, 2015: unpublished observations). Similar to the findings from the current study, social identity in that study was shown to be an emergent property of facilitated interaction that was based on perceptions of group member similarity and shared experience.

Participants and group facilitators in the current study identified several features relating to the design of the intervention session (figure 1) that highlight how the above basic principles of establishing social identity can be implemented in group interventions. In line with recent Medical Research Council guidance on process evaluation in complex interventions, ${ }^{11}$ these features can be seen as reflecting fidelity issues (eg, delivery of group interventions) and also mechanisms of impact (eg, how participant engagement and group interaction are achieved). Some of the design features participants identified were regarded as 'fixed' features, or what might be termed form issues, in the sense that they could be planned in advance of the session (eg, group size, mid-session breaks). Of particular note is the finding that involving a member of the target population in the organisation of the session (eg, recruitment) contributed to participant engagement with the intervention. Employing a group 'champion' in this way may encourage a more rapid 'settling in' of participants and promote early social interaction leading to feelings of belonging. Other features related to the perceived critical role of the group facilitators-both in terms of their provision of key content relative to the intended health outcomes (in our case, leading musical activities) and their 'flexible' delivery of the session, for example, by managing the expectations of group members and responding to their needs in situ. This flexibility (or function issues) was strongly valued by participants and reflects other research that has considered the role of group facilitators in managing groups $^{22}$ (Tarrant et al, 2015: unpublished observations). It also highlights the importance of ensuring that those who are responsible for delivering group interventions are appropriately skilled in group leadership: facilitators may require specific training to become entrepreneurs of identity. ${ }^{21}$

A clear strength of the current study is its triangulation of findings, drawing on data from three sources (focus group, interviews and researcher observations). While the conclusions drawn here about how to nurture social identity in group interventions are based on data from a single session of an intervention for people with a specific long-term health condition, they accord with some of the general processes pertaining to group formation that have been discussed elsewhere. ${ }^{35}$ Our findings also resonate with those from other research programmes that have started to explore the role of social and psychological connections between participants in intervention groups, ${ }^{8}$ and the potential of music to facilitate these connections. ${ }^{36}$ Nonetheless, future research should seek to test our conclusions in other healthcare contexts, particularly those where there are fewer preexisting similarities between group members or lower levels of initial homogeneity. Relatedly, while participants here were clear about the potential benefits of participating in a group intervention that is underpinned by shared social identity between group members, it is not possible to conclude that this participation actually impacted participants' health. Finally, we have articulated group processes conducive to the initial formation of social identity in an intervention group. How these processes evolve over time across the context of an intervention is an important consideration and is likely to depend both on the specific health condition and group members' individual experiences of the intervention and interactions with others receiving it. ${ }^{37}$ Our ongoing research is building on the work here to finalise the intervention specification such that it can be the subject of a randomised controlled trial with clear outcomes of value to people with aphasia.

This study should therefore be seen as a starting point for understanding the ways in which participants in new group interventions form psychological connections with 
one another, and it provides a guide to how these connections might be deliberately nurtured by creating the conditions for early active participant engagement. Facilitating the development of a positive and meaningful shared social identity among intervention participants may pave the way for the delivery of key intervention content pertinent to the intended health outcomes.

\section{Author affiliations}

${ }^{1}$ University of Exeter Medical School, University of Exeter, Exeter, UK

${ }^{2}$ Peninsula Collaboration for Leadership in Applied Health Research and Care (PenCLAHRC), South West Peninsula, UK

${ }^{3}$ Department of Psychology, Centre for Clinical Neuropsychology Research, University of Exeter, Exeter, UK

${ }^{4}$ Plymouth University Peninsula Schools of Medicine and Dentistry, Plymouth University, Plymouth, UK

\section{Twitter Follow PenCLAHRC at @PenCLAHRC}

Acknowledgements The authors thank Jane Adamson, lan Parsons, Bev Snowden, Rachel Thame and Anna Batson for their contributions to the development of the intervention session plan, a local aphasia network chairperson for assistance in participant recruitment and Plymouth Music Zone for providing music facilitators and use of their facilities for the singing session and focus group/interviews.

Contributors MT was a project lead; and involved in the study conception and design; intervention development; data collection; interpretation of results; manuscript write-up. KW was involved in the data collection; data analysis and interpretation of results; manuscript write-up. CC was involved in the intervention development; study design; interpretation of results; manuscript write-up. SD was involved in the study design; data analysis; interpretation of results; manuscript write-up. VAG was involved in the intervention development; interpretation of results; manuscript write-up. KS was involved in the study conception and design; data collection; interpretation of results; manuscript write-up. TS was involved in the study design; data collection; led focus group and interviews; transcription of interview/focus group data; data analysis; interpretation of results; manuscript write-up.

Funding This research was funded by the National Institute for Health Research (NIHR) Collaboration for Leadership in Applied Health Research and Care South West Peninsula. The views expressed are those of the authors and not necessarily those of the NHS, the NIHR or the Department of Health.

Competing interests None declared.

Ethics approval University of Exeter Psychology Ethics Committee, Ref: 2014/514.

Provenance and peer review Not commissioned; externally peer reviewed.

Data sharing statement No additional data are available.

Open Access This is an Open Access article distributed in accordance with the Creative Commons Attribution Non Commercial (CC BY-NC 4.0) license, which permits others to distribute, remix, adapt, build upon this work noncommercially, and license their derivative works on different terms, provided the original work is properly cited and the use is non-commercial. See: http:// creativecommons.org/licenses/by-nc/4.0/

\section{REFERENCES}

1. Lacasse $Y$, Goldstein R, Lasserson TJ, et al. Pulmonary rehabilitation for chronic obstructive pulmonary disease. Cochrane Database Syst Rev 2009;18:CD003793.

2. Paul-Ebhohimhen $\mathrm{V}$, Avenell A. A systematic review of the effectiveness of group versus individual treatments for adult obesity. Obes Facts 2009;2:17-24.

3. Wakefield JR, Bickley S, Sani F. The effects of identification with a support group on the mental health of people with multiple sclerosis. J Psychosom Res 2013;74:420-6.
4. Beesley $\mathrm{K}$, White $\mathrm{JH}$, Alston MK, et al. Art after stroke: the qualitative experience of community dwelling stroke survivors in a group art programme. Disabil Rehabil 2011;33:2346-55.

5. Code C, Torney A, Gildea-Howardine E, et al. Outcome of a one-month therapy intensive for chronic aphasia: variable individual responses. Semin Speech Lang 2010;31:21-33.

6. Greaves CJ, Campbell JL. Supporting self-care in general practice. Br J Gen Pract 2007;57:814-21.

7. Borek AJ, Abraham C, Smith JR, et al. A checklist to improve reporting of group-based behaviour-change interventions. BMC Pub Health 2015;15:963.

8. Gessel SB, Barkin SL, Valente TW. Social network diagnostics: a tool for monitoring group interventions. Implement $\mathrm{SCl}$ 2013;8:116.

9. A framework for development and evaluation of RCTs for complex interventions to improve health. Medical Research Council, 2000. http://www.mrc.ac.uk/documents/pdf/rcts-for-complexinterventions-to-improve-health/ (accessed 28 Jul 2015)

10. Craig P, Dieppe P, Macintyre S, et al. Developing and evaluating complex interventions: new guidance. Medical Research Council, 2008. http://www.mrc.ac.uk/documents/pdf/complex-interventionsguidance/ (accessed 28 Jul 2015).

11. Moore GF, Audrey S, Barker M, et al. Process evaluation of complex interventions: Medical Research Council guidance. BMJ 2015;350: h1258.

12. Cruice M, Worral L, Hickson L. Quantifying aphasic people's social lives in the context of non-aphasic peers. Aphasiology 2006;20:1210-25.

13. Hilari K. The impact of stroke: are people with aphasia different to those without? Disabil Rehabil 2011;33:211-18.

14. Auerbach J, Benezra A. Therapeutic recreation and the rehabilitation of the stroke patient. Loss Grief Care 1998;8:123-8.

15. Cruwys T, Haslam SA, Dingle GA, et al. Feeling connected again: interventions that increase social identification reduce depression symptoms in community and clinical settings. $J$ Affect Disord 2014;159:139-46.

16. Gleibs IH, Haslam C, Jones JM, et al. No country for old men? The role of a 'Gentlemen's Club' in promoting social engagement and psychological well-being in residential care. Aging Ment Health 2011;15:456-66.

17. Tajel $\mathrm{H}$, Turner JC. An integrated theory of intergroup conflict. In: Austin WG, Worchel S, eds. The social psychology of intergroup relations. Monterey, CA: Brooks-Cole, 1979:33-47.

18. Haslam SA, Jetten J, Postmes T, et al. Social identity, health, and well-being: an emerging agenda for applied psychology. Appl Psychol-Int Rev 2009;58:1-23.

19. Sani F, Madhok V, Norbury M, et al. Greater number of group identifications is associated with healthier behaviour: evidence from a Scottish community sample. Br J Health Psychol 2015;20:466-81.

20. Tarrant M, Hagger MS, Farrow CV. Promoting positive orientation towards health through social identity. In: Jetten J, Haslam SA, Haslam C, eds. The social cure: identity, health, and well-being. New York: Psychology Press, 2012:39-54.

21. Haslam SA, Postmes T, Ellemers N. More than a metaphor: organizational identity makes organizational life possible. $\mathrm{Br} \mathrm{J}$ Manage 2003;14:357-69.

22. Haslam SA, Reicher SD, Platow MJ. The new psychology of leadership: identity, influence and power. Hove, UK: Psychology Press, 2010.

23. Sani $F$. When subgroups secede: extending and refining the social psychological model of schism in groups. Pers Soc Psychol $B$ 2005;31:1074-86.

24. Van Vugt M, Hart CM. Social identity as social glue: the origins of group loyalty. J Pers Soc Psychol 2004;86:585-98.

25. Clift $\mathrm{S}$. Creative arts as a public health resource: moving from practice-based research to evidence-based practice. Perspect Public Health 2012;132:120-7.

26. Clift S, Hancox G, Staricoff R, et al. Singing and health: summary of a systematic mapping and review of non-clinical research. Sidney De Haan Research Centre for Arts and Health, 2008. http://www. creativityaustralia.org.au/wp-content/uploads/2012/05/ Report-5-Systematic-Mapping-and-Review.pdf (accessed $28 \mathrm{Jul}$ 2015).

27. Clift S, Hancox G. The significance of choral singing for sustaining psychological wellbeing: findings from a survey of choristers in England, Australia and Germany. Music Perform Res 2010;3: 79-96.

28. Dingle GA, Brander C, Ballantyne J, et al. "To be heard": the social and mental health benefits of choir singing for disadvantaged adults. Psychol Music 2013;41:405-21. 
29. Crotty M. The foundations of social research: meaning and perspective in the research process. Thousand Oaks, CA: Sage, 2003.

30. Grbich C. Qualitative research in health: an introduction. St Leonards, Australia: Allen \& Unwin, 1999.

31. Clemensen J, Larsen SB, Kyng M, et al. Participatory design in health sciences using cooperative experimental methods in developing health services and computer technology. Qual Health Res 2007;17:122-30.

32. Wherton J, Sugarhood P, Procter R, et al. Co-production in practice: how people with assisted living needs can help design and evolve technologies and services. Implement Sci 2015;10:75.

33. Holbrook MB, Schindler RM. Some exploratory findings on the development of musical tastes. J Consum Res 1989;16: $119-24$.
34. Ritchie J, Spencer L. Qualitative data analysis for applied policy research. In: Bryman A, Burgess R, eds. Analyzing qualitative data. London: Sage, 1994:173-94.

35. Postmes T, Haslam SA, Swaab RI. Social influence in small groups: an interactive model of social identity formation. Eur Rev Soc Psychol 2005;16:1-42.

36. Loersch C, Arbuckle NL. Unraveling the mystery of music: music as an evolved group process. J Pers Soc Psychol 2013;105:777-98.

37. Cruwys T, Haslam SA, Fox NE, et al. "That's not what we do": evidence that normative change is a mechanism of action in group interventions. Behav Res Ther 2015;65:11-17.

38. Hornsey MJ, Dwyer L, Oei TPS, et al. Group processes and outcomes in group psychotherapy: is it time to let go of "cohesiveness"? Int J Group Psychoth 2009;59:267-78. 